Pacific Journal of Mathematics

A DUAL RELATIONSHIP BETWEEN GENERALIZED
ABEL-GONČAROV BASES AND CERTAIN PINCHERLE BASES 


\title{
A DUAL RELATIONSHIP BETWEEN GENERALIZED ABEL-GONČAROV BASES AND CERTAIN PINCHERLE BASES
}

\section{F. HASLINGER}

\begin{abstract}
Recent results on Abel-Gonçarov polynomial expansions are applied to study the representability of holomorphic functions as infinite series in a given Pincherle sequence. As a generalization of the ordinary derivative we consider the so-called Gel'fond-Leont'ev derivative $\mathscr{D}$. We take the exponential function with respect to the derivative $\mathscr{D}$ and use a duality principle in order to investigate the completeness of the system $E_{n}(z)=z^{n} E\left(\lambda_{n} z\right)$ in the space $\mathscr{F}_{r}$ of functions holomorphic on the interior of the disc of radius $r \leqq \infty$. Finally we study the uniqueness of the representability of holomorphic functions as infinite series in the system $E_{n}$.
\end{abstract}

1. Basic facts and definitions. Let $0<r \leqq \infty$. We shall be interested in the nuclear Fréchet space $\mathscr{F}_{r}$ consisting of all functions holomorphic on the open disk of radius $r$, equipped with the topology of uniform convergence on compact sets (see [15]). For the topology in the space $\mathscr{F}_{r}$, we can take the norms $\|\cdot\|_{r^{\prime}}, 0<r^{\prime}<r$ given by $\|f\|_{r^{\prime}}=\max \left\{|f(z)|:|z|=r^{\prime}\right\}, \quad f \in \mathscr{F}_{r}$. It is easily seen that by Cauchy's estimates that system of norms $\left\{\|\cdot\|_{r^{\prime}}, 0<r^{\prime}<r\right\}$ is equivalent to the system of norms $\left\{\|\| \cdot \|_{r^{\prime}}, 0<r^{\prime}<r\right\}$, where

$$
\|\| f \|_{r^{\prime}}=\sup _{0 \leqq k<\infty}\left|a_{k}\right| r^{\prime k}
$$

for $f \in \mathscr{F}_{r}$ with Taylor series expansion

$$
f(z)=\sum_{k=0}^{\infty} a_{k} z^{k} .
$$

We recall that two systems of seminorms $\left\{\|\cdot\|_{p}, p \in P\right\}$ and $\left\{\|\| \cdot \|_{p}\right.$, $p \in P\}$ are equivalent, if for each $p \in P$ there exists a constant $K_{p}$ depending on $p$ and $q \in P$ such that $\|\cdot\|_{p} \leqq K_{p}\|\cdot\| \|_{q}$, and if for each $p^{\prime} \in P$ there exists a constant $K_{p^{\prime}}$ depending on $p^{\prime}$ and $q^{\prime} \in P$ such that $\|\cdot\|\left\|_{p^{\prime}} \leqq K_{p^{\prime}}\right\| \cdot \|_{q^{\prime}}$.

A sequence $\left(f_{n}\right)_{n=0}^{\infty}$ in $\mathscr{F}_{r}$ is complete if the set of all finite linear combinations of the functions $f_{n}$ is dense in $\mathscr{F}_{r}$. And $\left(f_{n}\right)_{n=0}^{\infty}$ is a basis in $\mathscr{F}_{r}$ if each $f \in \mathscr{F}_{r}$ has a representation

$$
f=\sum_{n=0}^{\infty} c_{n} f_{n},
$$

where $\left(c_{n}\right)_{n=0}^{\infty}$ is a sequence of scalars uniquely determined by $f$ and 
the infinite series converges in the topology of $\mathscr{F}_{r}$. Two bases $\left(f_{n}\right)_{n=0}^{\infty}$ and $\left(g_{n}\right)_{n=0}^{\infty}$ are equivalent if $\sum_{n=0}^{\infty} c_{n} f_{n}$ converges in $\mathscr{F}_{r}$ if and only if $\sum_{n=0}^{\infty} c_{n} g_{n}$ converges in $\mathscr{F}_{r}$. As is well known, the sequence of the functions $\left(z^{n}\right)_{n=0}^{\infty}$ constitutes a basis for any space $\mathscr{F}_{r}(0<$ $r \leqq \infty)$. A basis $\left(f_{n}\right)_{n=0}^{\infty}$ is called proper if it is equivalent to $\left(z^{n}\right)_{n=0}^{\infty}$ (see [1], [4]).

M. Arsove [1], in a series of papers, has considered Pincherle sequences $\left(f_{n}\right)_{n=0}^{\infty}$ in which $f_{n}$ has the form

$$
f_{n}(z)=z^{n} \psi_{n}(z), \quad n=0,1,2, \cdots
$$

where each function $\psi_{n} \in \mathscr{F}_{r}$ and $\psi_{n}(0)=1$. Recently, in [1] Arsove and in [4] Dubinsky studied linear Pincherle sequences (see also [9])

$$
f_{n}(z)=z^{n}\left(1-\frac{z}{z_{n}}\right), \quad n=0,1,2, \cdots .
$$

In this paper we investigate the problem of determining when a system

$$
E_{n}(z)=z^{n} E\left(\lambda_{n} z\right), \quad n=0,1,2, \cdots
$$

is complete in $\mathscr{F}_{r}$, when it is not complete and when it is a basis, even a proper basis in $\mathscr{F}_{r}$. Here $\left(\lambda_{n}\right)_{n=0}^{\infty}$ is a sequence of scalars and $E$ is a generalized exponential function corresponding to a so-called Gel'fond-Leont'ev derivative $\mathscr{D}$ (see [8]).

Let $\left(d_{k}\right)_{k=1}^{\infty}$ denote a nondecreasing sequence of positive numbers. The Gel'fond-Leont'ev derivative $\mathscr{D}$ is defined by

$$
\mathscr{f} f(z)=\sum_{k=1}^{\infty} d_{k} a_{k} z^{k-1},
$$

where

$$
f(z)=\sum_{k=0}^{\infty} a_{k} z^{k}
$$

As in [2] or [7] we suppose that the sequence $\left(d_{k}\right)_{k=1}^{\infty}$ satisfies the following condition

$$
\left(d_{k+1} / d_{k}\right)_{k=1}^{\infty} \text { is nonincreasing and has limit } 1 .
$$

Then it follows

$$
\lim _{k \rightarrow \infty} d_{k}^{1 / k}=1
$$

Thus if $f$ has radius of convergence $c(f)$ then 


$$
\mathscr{D} f(z)=\sum_{k=1}^{\infty} d_{k} a_{k} z^{k-1}
$$

has also radius of convergence $c(f)$.

The operator $\mathscr{D}$ corresponds to the ordinary derivative when $d_{k}=k(k=1,2, \cdots)$ and to the shift operator $\mathscr{S}$ when $d_{k}=1$ $(k=1,2, \cdots) . \mathscr{S}$ is defined by

$$
\mathscr{S} f(z)=\sum_{k=1}^{\infty} a_{k} z^{k-1}
$$

The operators $\mathscr{D}^{n}(n=1,2, \cdots)$ are the successive iterates of $\mathscr{D}$ and we have

$$
\mathscr{D}^{n} f(z)=\sum_{k=n}^{\infty} \frac{e_{k-n}}{e_{k}} a_{k} z^{k-n},
$$

where $e_{0}=d_{0}=1$ and $e_{n}=\left(d_{1} d_{2} \cdots d_{n}\right)^{-1}$ for $n \geqq 1$.

We write

$$
E(z)=\sum_{k=0}^{\infty} e_{k} z^{k}
$$

and note that this function bears the same relationship to the operator $\mathscr{D}$ that the exponential function bears to the ordinary differentiation. This means

$$
E(0)=1 \text { and } \mathscr{D} E(z)=E(z) .
$$

Let $R=c(E)$, then, by the monotonicity of the sequence $\left(d_{k}\right)_{k=1}^{\infty}$ we have (see [2])

$$
R=\lim _{k \rightarrow \infty} d_{k}=\sup _{1 \leqq k<\infty} d_{k} .
$$

The $E$-type of a function $f(z)=\sum_{k=0}^{\infty} \alpha_{k} z^{k}$ is the number

$$
\tau_{E}(f)=\limsup _{k \rightarrow \infty}\left|a_{k} / e_{k}\right|^{1 / k} .
$$

If $R<\infty$ then

$$
\tau_{E}(f)=\frac{R}{c(f)}
$$

Now we define for a sequence $\left(\lambda_{k}\right)_{k=0}^{\infty}$ of scalars the polynomials $Q_{n}\left(z ; \lambda_{0}, \cdots, \lambda_{n-1}\right)$ by $Q_{0}(z) \equiv 1$ and

$$
Q_{n}\left(z ; \lambda_{0}, \cdots, \lambda_{n-1}\right)=e_{n} z^{n}-\sum_{k=0}^{n-1} e_{n-k} \lambda_{k}^{n-k} Q_{k}\left(z ; \lambda_{0}, \cdots, \lambda_{k-1}\right) .
$$

It is easily seen that 


$$
e_{n} z^{n}=\sum_{k=0}^{n} e_{n-k} \lambda_{k}^{n-k} Q_{k}\left(z ; \lambda_{0}, \cdots, \lambda_{k-1}\right) .
$$

The polynomials $Q_{n}\left(z ; \lambda_{0}, \cdots, \lambda_{n-1}\right)$ are called the Gončarov polynomials belonging to the operator $\mathscr{D}$ (see [2]). They reduce to the ordinary Gončarov polynomials if $d_{k}=k(k=1,2, \cdots)$ and the remainder polynomials if $d_{k}=1(k=1,2, \cdots)$.

One verifies easily that

$$
\mathscr{D}^{k} Q_{n}\left(\lambda_{k} ; \lambda_{0}, \cdots, \lambda_{n-1}\right)=\delta_{n k}
$$

Therefore the polynomials $Q_{n}\left(z ; \lambda_{0}, \cdots, \lambda_{n-1}\right)$ are biorthogonal to the linear functionals

$$
\mathscr{L}_{n}(f)=\mathscr{D}^{n} f\left(\lambda_{n}\right) \text {. }
$$

Now we consider the problem under which conditions the polynomials $Q_{n}\left(z ; \lambda_{0}, \cdots, \lambda_{n-1}\right)$ constitute a basis in $\mathscr{F}_{r}$, i.e.,

$$
f(z)=\sum_{n=0}^{\infty} \mathscr{D}^{n} f\left(\lambda_{n}\right) Q_{n}\left(z ; \lambda_{0}, \cdots, \lambda_{n-1}\right)
$$

for each $f \in \mathscr{F}_{r}$ and the infinite series converges in the topology of $\mathscr{F}_{r}$.

In this connection the Whittaker constant $W(\mathscr{D})$ belonging to the operator $\mathscr{D}$ plays an important role. We can introduce the Whittaker constant $W(\mathscr{D})$ by

$$
W(\mathscr{D})=\left(\sup _{1 \leq n<\infty} H_{n}^{1 / n}\right)^{-1},
$$

where

$$
H_{n}=\max \left|Q_{n}\left(0 ; \lambda_{0}, \cdots, \lambda_{n-1}\right)\right| \quad(n=1,2, \cdots)
$$

and the maximum is taken over all sequences $\left(\lambda_{k}\right)_{k=0}^{n-1}$ whose terms lie on the unit circle (see Buckholtz and Frank [2]).

The Whittaker constant satisfies the inequality (see [2])

$$
0<\frac{d_{1}}{2} \leqq W(\mathscr{D})<d_{1}
$$

In [7], Frank and Shaw investigated the above problem and the following theorem is an easy consequence of their Theorem $\mathrm{A}$ in [7]: that

Theorem A. Let $\left(\lambda_{n}\right)_{n=0}^{\infty}$ be a sequence of complex numbers such

$$
\left|\lambda_{n}\right| \leqq \frac{e_{n+1}}{e_{n}} s, \quad n=0,1,2, \cdots
$$


for a real number $s>0$. Then the Gončarov polynomials constitute a basis in any space $\mathscr{F}_{r}$ for

$$
r>\frac{s}{W(\mathscr{D})} .
$$

The following theorem, which is again an easy consequence of a theorem due to Buckholtz and Frank [3], shows that Theorem A is sharp in a certain sense:

THEOREM B. Let $r$ and $s$ be positive numbers such that

$$
\frac{s}{W(\mathscr{D})}>r
$$

Then there exists a holomorphic function $F$ of radius of convergence $r$ such that $\mathscr{D}^{n} F$ has a zero in $|\boldsymbol{z}| \leqq\left(e_{n+1} / e_{n}\right)$ s for all but finitely many $n$.

In the following we will use Theorem A and Theorem B and two duality principles for $\mathscr{F}_{r}$ in order to investigate the behavior of the Pincherle sequences

$$
E_{n}(z)=z^{n} E\left(\lambda_{n} z\right) \quad n=0,1,2, \cdots,
$$

where $E$ is the exponential function belonging to the operator $\mathscr{D}$ and $\left(\lambda_{n}\right)_{n=0}^{\infty}$ is a given sequence of scalars.

2. Completeness of the system $\left\{z^{n} E\left(\lambda_{n} z\right)\right\}$. Let $E \in \mathscr{F}_{R}^{-}$ $(0<R<\infty)$ with the power series expansion

$$
E(z)=\sum_{k=0}^{\infty} e_{k} z^{k} \text { and } \quad \limsup _{k \rightarrow \infty}\left|e_{k}\right|^{1 / k}=\frac{1}{R} .
$$

We suppose that $e_{0}=1$ and $e_{k}>0$ for $k=1,2, \cdots$.

In the sequel, we will always require that the sequence $\left(e_{k}\right)_{k=0}^{\infty}$ satisfies the following conditions:

(2.1a) $\left(e_{k-1} / e_{k}\right)_{k=1}^{\infty}$ is nondecreasing;

(2.1b) $\left(e_{k}^{2} / e_{k-1} e_{k+1}\right)_{k=1}^{\infty}$ is nonincreasing and has limit 1 (compare (1.1)).

From condition (2.1a) we have

$$
\lim _{k \rightarrow \infty}\left(e_{k} / e_{k-1}\right)=\frac{1}{R}
$$

since $E \in \mathscr{F}_{R}$. 
THEOREM 1. Let $\left(\lambda_{n}\right)_{n=0}^{\infty}$ be a sequence of complex numbers such that

$$
\left|\lambda_{n}\right| \leqq \frac{e_{n+1}}{e_{n}} s \quad n=0,1,2, \cdots
$$

for a real number $s>0$. Then the system $\left\{z^{n} E\left(\lambda_{n} z\right)\right\}_{n=0}^{\infty}$ is complete in any space $\mathscr{F}_{r}$ for $R / r \geqq s / W(\mathscr{D})$.

Proof. Here we use the following well known form of the Hahn-Banach theorem: A subset $G \subseteq \mathscr{F}_{r}$ is dense in $\mathscr{F}_{r}$ if and only if for each continuous linear functional $L$ on $\mathscr{F}_{r}$ such that $L(g)=0$ for each $g \in G$ it follows that $L=0$.

Let $\left\{\left(e_{k}\right)_{k=0}^{\infty}, r\right\}$ denote the space of all holomorphic functions $h(z)=\sum_{k=0}^{\infty} h_{k} z^{k}$ with the property

$$
\limsup _{k \rightarrow \infty}\left|h_{k} / e_{k}\right|^{1 / k}<r .
$$

This means that the functions $h \in\left\{\left(e_{k}\right)_{k=0}^{\infty}, r\right\}$ are holomorphic on the disk $|z| \leqq R / r$, since

$$
\left.\limsup _{k \rightarrow \infty}\left|h_{k}\right| e_{k}\right|^{1 / k}=R \limsup _{k \rightarrow \infty}\left|h_{k}\right|^{1 / k}<r,
$$

and on the other hand that the function

$$
h_{E}(z)=\sum_{k=0}^{\infty} \frac{h_{k}}{e_{k}} z^{-k-1}
$$

is holomorphic for $|z| \geqq \imath$.

A duality between $\mathscr{F}_{r}$ and $\left\{\left(e_{k}\right)_{k=0}^{\infty}, r\right\}$ is defined by the bilinear forms

$$
\langle g, h\rangle=\frac{1}{2 \pi i} \int_{r} g(z) h_{E}(z) d z,
$$

where $g \in \mathscr{F}_{r}, h \in\left\{\left(e_{k}\right)_{k=0}^{\infty}, r\right\}$ and $\gamma$ is a circle contained in the intersection of the domain of holomorphy of $g$ with the domain of holomorphy of $h_{E}$.

Formula (2.2) gives the general form of the continuous linear functionals on $\mathscr{F}_{r}$ (see [6] or [12]).

Now let $L \in \mathscr{F}_{r}^{\prime}$ such that $L\left(E_{n}\right)=0$ for $n=0,1,2, \cdots$, where $E_{n}(z)=z^{n} E\left(\lambda_{n} z\right)$. Then there exists a function $h \in\left\{\left(e_{k}\right)_{l=0}^{\infty}, r\right\}$ such that

$$
\begin{aligned}
L\left(E_{n}\right) & =\frac{1}{2 \pi i} \int_{\gamma} z^{n} E\left(\lambda_{n} z\right) h_{E}(z) d z=\frac{1}{2 \pi i} \int_{r}\left(\sum_{k=0}^{\infty} e_{k} \lambda_{n}^{k} z^{k+n}\right)\left(\sum_{k=0}^{\infty} \frac{h_{k}}{e_{k}} z^{-k-1}\right) d z \\
& =\sum_{k=n}^{\infty} \frac{e_{k-n}}{e_{k}} \lambda_{n}^{k-n} h_{k}=\mathscr{D}^{n} h\left(\lambda_{n}\right) .
\end{aligned}
$$


By condition (2.1a) and inequality (1.5) we have

$$
\left|\lambda_{n}\right| \leqq \frac{e_{n+1}}{e_{n}} s \leqq e_{1} s<\frac{s}{W(\mathscr{D})} \leqq \frac{R}{r},
$$

which implies that $E_{n} \in \mathscr{F}_{r}$ for $n=0,1,2, \cdots$.

Since

$$
H=\left(\lim _{k \rightarrow \infty} \sup \left|h_{k}\right|^{1 / k}\right)^{-1}>\frac{R}{r}
$$

the assumption $R / r \geqq s / W(\mathscr{D})$ implies that the corresponding Gončarov-polynomials constitute a basis in $\mathscr{F}_{I I}$ (see Theorem A). By the uniqueness-property of a basis we have $h \equiv 0$ if $\mathscr{D}^{n} h\left(\lambda_{n}\right)=0$ for $n=0,1,2, \cdots$. Now it follows $L=0$, which completes our proof.

In the next theorem we show that Theorem 1 is sharp in a certain sense:

THeOREM 2. Let $r$ and $s$ be positive numbers such that $s e_{1}<$ $R / r<s / W(\mathscr{D})$. Then there exists a sequence of complex numbers $\left(\lambda_{n}\right)_{n=0}^{\infty}$ with the property

$$
\left|\lambda_{n}\right| \leqq \frac{e_{n+1}}{e_{n}} s
$$

such that the functions $E_{n}(z)=z^{n} E\left(\lambda_{n} z\right)$ are in $\mathscr{F}_{r}$ but are not complete in $\mathscr{F}_{r}$.

Proof. We have to show that there exists a continuous linear functional $L_{0} \neq 0$ on $\mathscr{F}_{r}$ such that $L_{0}\left(E_{n}\right)=0$ for $n=0,1,2, \cdots$, where

$$
E_{n}(z)=z^{n} E\left(\lambda_{n} z\right) \text { for } n=0,1,2, \cdots
$$

and $\left(\lambda_{n}\right)_{n=0}^{\infty}$ is a suitable sequence of complex numbers. In view of the proof of Theorem 1 it suffices to show that there exists a function

$$
h_{0} \in\left\{\left(e_{k}\right)_{k=0}^{\infty}, r\right\}
$$

such that $\mathscr{D}^{n} h_{0}\left(\lambda_{n}\right)=0$ for $n=0,1,2, \cdots$ and $h_{0} \not \equiv 0$.

In order to find such a function $h_{0}$ we apply Theorem B: by our assumption

$$
\frac{R}{r}<\frac{s}{W(\mathscr{D})}
$$

we can find a number $H_{0}$ such that 


$$
\frac{R}{r}<H_{0}<\frac{s}{W(\mathscr{D})}
$$

and by Theorem $\mathrm{B}$ there exists a function $\tilde{h}_{0}$ with $c\left(\tilde{h}_{0}\right)=H_{0}$ such that $\mathscr{D}^{n} \tilde{h}_{0}$. has a zero in

$$
|z| \leqq \frac{e_{n+1}}{e_{n}} s
$$

for all but finitely many $n$.

This implies that we can find a sequence $\left(\lambda_{n}\right)_{n=0}^{\infty}$ of complex numbers with

$$
\left|\lambda_{n}\right| \leqq \frac{e_{n+1}}{e_{n}} s
$$

for $n=0,1,2, \cdots$ such that $\left|\mathscr{D}^{n} \tilde{h}_{0}\left(\lambda_{n}\right)\right|<\infty$ for $0 \leqq n \leqq N$ (take for instance $\lambda_{n}=0$ for $\left.0 \leqq n \leqq N\right)$ and $\mathscr{D}^{n} \widetilde{h}_{0}\left(\lambda_{n}\right)=0$ for $n>N$, where $N$ is a suitable natural number. Since $e_{1} s<R / r$, we have $\left|\lambda_{n}\right| \leqq\left(e_{n+1} / e_{n}\right) s \leqq e_{1} s<R / r$, which implies that $E_{n} \in \mathscr{F}_{r}$ for $n=$ $0,1,2, \cdots$.

Now define a polynomial $p_{0}$ by

$$
p_{0}(z)=\sum_{n=0}^{N} \mathscr{D}^{n} \tilde{h}_{0}\left(\lambda_{n}\right) Q_{n}\left(z ; \lambda_{0}, \cdots, \lambda_{n-1}\right)
$$

Then $p_{0}$ is a polynomial of degree not greater than $N$ and has the property

$$
\mathscr{D}^{n} p_{0}\left(\lambda_{n}\right)=\mathscr{D}^{n} \tilde{h}_{0}\left(\lambda_{n}\right) \text { for } 0 \leqq n \leqq N
$$

and $\mathscr{D}^{n} p_{0}\left(\lambda_{n}\right)=0$ for $n>N($ see part 1$)$.

We set now

$$
h_{0}=\widetilde{h}_{0}-p_{0}
$$

then

$$
\mathscr{D}^{n} h_{0}\left(\lambda_{n}\right)=0 \text { for } n=0,1,2, \cdots
$$

and $c\left(h_{0}\right)=H_{0}$.

If we write

$$
h_{0}(z)=\sum_{k=0}^{\infty} h_{0, k} z^{k}
$$

then

$$
\limsup _{k \rightarrow \infty}\left|h_{0, k} / e_{k}\right|^{1 / l}<r
$$

since $H_{0}>R / r$. This means $h_{0} \in\left\{\left(e_{k}\right)_{k=0}^{\infty}, r\right\}$. So if we set 


$$
L_{0}(g)=\left\langle g, h_{0}\right\rangle=\frac{1}{2 \pi i} \int_{r} g(z)\left(h_{0}\right)_{E}(z) d z
$$

then $L_{0}\left(E_{n}\right)=0$ for $n=0,1,2, \cdots$ and $L_{0} \neq 0$.

The desired conclusion now follows again from the Hahn-Banach theorem.

3. Uniqueness of the representation by the system $\left\{z^{n} E\left(\lambda_{n} z\right)\right\}$. The purpose of this part is to derive conditions under which the system $\left\{z^{n} E\left(\lambda_{n} z\right)\right\}$ constitutes a basis in its closed linear hull in a certain space $\mathscr{F}_{r}$. In order to do this we use a dual relationship between basis theory and interpolation theory developed by M. M. Dragilev, V. P. Zaharjuta and Ju. F. Korobeinik in 1974 (see [4]):

Let $X$ be a nuclear Fréchet space with a topology given by a family of seminorms $\left\{\|\cdot\|_{p}, p \in P\right\}$; let $X^{\prime}$ be the strong dual space. We consider two sequence spaces generated by a sequence $\left\{x_{n}\right\}_{n=0}^{\infty}$ of nonzero elements of $X$ :

$$
\mathscr{E}=\left\{\boldsymbol{c}=\left(c_{n}\right)_{n=0}^{\infty}:|c|_{p}:=\sum_{n=0}^{\infty}\left|\boldsymbol{c}_{n}\right|\left\|x_{n}\right\|_{p}<\infty \text {, for each } p \in P\right\}
$$

with the topology determined by the family of seminorms $\left\{|c|_{p}, p \in P\right\}$, and

$$
\mathscr{E}^{\prime}=\left\{c^{\prime}=\left(c_{n}^{\prime}\right)_{n=0}^{\infty}: \text { there exists a } p \in P \text { with }\left|c^{\prime}\right|_{y}^{\prime}:=\sup _{n} \frac{\left|c_{n}^{\prime}\right|}{\left\|x_{n}\right\|_{p}}<\infty\right\}
$$

with the topology of the strong dual with respect to duality, given by the formula

$$
\left\langle c, c^{\prime}\right\rangle=\sum_{n=0}^{\infty} c_{n} c_{n}^{\prime}
$$

Theorem C. (See [4], [12].) Let $X$ be a nuclear Fréchet space. A sequence $\left\{x_{n}\right\}_{n=0}^{\infty}$ constitutes a basis in its closed linear hull in $X$ if and only if for each sequence $\left(t_{n}\right)_{n=0}^{\infty} \in \mathscr{E}^{\prime}$ there exists $x^{\prime} \in X^{\prime}$ such that

$$
x^{\prime}\left(x_{n}\right)=t_{n} \quad \text { for } \quad n=0,1,2, \cdots .
$$

(In this case one says that the interpolation problem $\left(X^{\prime},\left\{x_{n_{3}}\right\}_{n=0}^{\infty}\right)$ is solvable).

In the sequel we use Theorem $\mathrm{C}$ for the system $E_{n}(z)=z^{n} E\left(\lambda_{n} z\right)$ considered in part 2 .

THEOREM 3. Let $\left(\lambda_{n}\right)_{n=0}^{\infty}$ be a sequence of complex numbers such that 


$$
\left|\lambda_{n}\right| \leqq \frac{e_{n+1}}{e_{n}} s \quad n=0,1,2, \cdots .
$$

for a real number $s>0$. Then the system $\left\{z^{n} E\left(\lambda_{n} z\right)\right\}_{n=0}^{\infty}$ constitutes a basis in $\mathscr{F}_{r}$ for any $r>0$ with the property $R / r \geqq s / W(\mathscr{D})$.

Proof. In order to apply the above principle we remark that Theorem $C$ says that $\left\{E_{n}\right\}_{n=0}^{\infty}$ constitutes a basis in its closed linear hull if and only if for each sequence $\left(t_{n}\right)_{n=0}^{\infty}$ with the property

$$
\left|t_{n}\right| \leqq K\left\|E_{n}\right\|_{r^{\prime}} \quad n=0,1,2, \cdots,
$$

where $r^{\prime}<r$ and $K$ is a constant only depending on $r^{\prime}$, there exists a continuous linear functional $L \in \mathscr{F}_{r}^{\prime}$ represented by a function $h \in\left\{\left(e_{k}\right)_{k=0}^{\infty}, r\right\}$ such that

$$
L\left(E_{n}\right)=\left\langle E_{n}, h\right\rangle=\mathscr{D}^{n} h\left(\lambda_{n}\right)=t_{n},
$$

for $n=0,1,2, \cdots$.

We take a sequence $\left(t_{n}\right)_{n=0}^{\infty}$ such that inequality (3.1) holds. Since the systems of norms $\left(\|\cdot\|_{r^{\prime}}, r^{\prime}<r\right)$ and $\left(\||\cdot|\|_{r^{\prime}}, r^{\prime}<r\right)$ are equivalent in $\mathscr{F}_{r}$, inequality (3.1) can be replaced by

$$
\left|t_{n}\right| \leqq K r^{\prime n} \sup _{k}\left(e_{k}\left|\lambda_{n}\right|{ }^{k} r^{\prime k}\right) \quad n=0,1,2, \cdots .
$$

This follows from the fact that

$$
E_{n}(z)=z^{n} \sum_{k=0}^{\infty} e_{k} \lambda_{n}^{k} z^{k}
$$

and by the definition of the norms $\|\cdot \cdot\| \|_{r^{\prime}}\left(r^{\prime}<r\right)$. Now we obtain

$$
\limsup _{n \rightarrow \infty}\left|t_{n}\right|^{1 / n} \leqq r^{\prime} \limsup _{n \rightarrow \infty}\left[\sup _{k}\left(e_{k}\left|\lambda_{n}\right|{ }^{k} r^{\prime k}\right)\right]^{1 / n} .
$$

By inequality (1.5) and the assumption $R / r \geqq s / W(\mathscr{D})$ we have $\left|\lambda_{n}\right|<R / r$ for $n=0,1,2, \cdots$. This means $E_{n} \in \mathscr{F}_{r}$ for $n=0,1,2, \cdots$, and

$$
\sup _{k}\left(e_{k}\left|\lambda_{n}\right|{ }^{k} r^{\prime k}\right) \leqq \sup _{k}\left(e_{k}\left(\frac{R}{r}\right)^{k} r^{\prime k}\right) .
$$

Since $(R / r) r^{\prime}<R$, we have

$$
\sup _{k}\left(e_{k}\left(\frac{R}{r}\right)^{k} r^{\prime k}\right)<K_{E},
$$

where $K_{E}$ is a constant depending on $E$.

This implies

$$
\limsup _{n \rightarrow \infty}\left|t_{n}\right|^{1 / n} \leqq r^{\prime}
$$


Now we obtain

$$
\limsup _{n \rightarrow \infty}\left|e_{n} t_{n}\right|^{1 / n} \leqq\left(\limsup _{n \rightarrow \infty} e_{n}^{1 / n}\right)\left(\limsup _{n \rightarrow \infty}\left|t_{n}\right|^{1 / n}\right) \leqq \frac{r^{\prime}}{R} .
$$

By Theorem A the Gončarov-polynomials $Q_{n}\left(z ; \lambda_{0}, \cdots, \lambda_{n-1}\right)$ constitute a basis in $\mathscr{F}_{R / r^{\prime}}$, since

$$
\frac{R}{r^{\prime}}>\frac{R}{r} \geqq \frac{s}{W(\mathscr{D})}
$$

Consider the polynomials

$$
e_{n}^{-1} Q_{n}\left(z ; \lambda_{0}, \cdots, \lambda_{n-1}\right) ;
$$

since

$$
e_{n}^{-1} Q_{n}\left(z ; \lambda_{0}, \cdots, \lambda_{n-1}\right)=z^{n}-\sum_{k=0}^{n-1} \frac{e_{n-k}}{e_{n}} \lambda_{k}^{n-k} Q_{k}\left(z ; \lambda_{0}, \cdots, \lambda_{k-1}\right),
$$

(see 1.3) it follows that the bases $\left\{e_{n}^{-1} Q_{n}\left(z ; \lambda_{0}, \cdots, \lambda_{n-1}\right)\right\}_{n=0}^{\infty}$ and $\left\{z^{n}\right\}_{n=0}^{\infty}$ are equivalent in $\mathscr{F}_{R / r^{\prime}}$, i.e.,

$$
\sum_{n=0}^{\infty} c_{n} e_{n}^{-1} Q_{n}\left(z ; \lambda_{0}, \cdots, \lambda_{n-1}\right)
$$

converges in $\mathscr{F}_{R / r^{\prime}}$ if and only if $\sum_{n=0}^{\infty} c_{n} z^{n}$ converges in $\mathscr{F}_{R / r^{\prime}}$ (see [14], pg. 188).

Now since lim $\sup _{n \rightarrow \infty}\left|e_{n} t_{n}\right|^{1 / n} \leqq r^{\prime} / R$, we have $\sum_{n=0}^{\infty} e_{n} t_{n} z^{n}$ converges in $\mathscr{F}_{R / r^{\prime}}$, and therefore $\sum_{n=0}^{\infty} t_{n} Q_{n}\left(z ; \lambda_{0}, \cdots, \lambda_{n-1}\right)$ converges in $\mathscr{F}_{R / r^{\prime}}$; in other words: there exists a function $h \in \mathscr{F}_{R / r^{\prime}}$ such that

$$
\mathscr{D}^{n} h\left(\lambda_{n}\right)=t_{n} \quad n=0,1,2, \cdots .
$$

The fact that $h \in \mathscr{F}_{R / r^{\prime}}$ implies that for

$$
h(z)=\sum_{k=0}^{\infty} h_{k} z^{k}
$$

we have

$$
\limsup _{k \rightarrow \infty}\left|h_{k}\right|^{1 / k} \leqq \frac{r^{\prime}}{R}<\frac{r}{R}
$$

and hence

$$
\limsup _{k \rightarrow \infty}\left|\frac{h_{k}}{e_{k}}\right|^{1 / k}<r .
$$

This means $h \in\left\{\left(e_{k}\right)_{k=0}^{\infty}, r\right\}$; now by the representation of the continuous linear functionals on $\mathscr{F}_{r}$ we see that there exists a continuous linear functional $L \in \mathscr{F}_{r}^{\prime}$ such that 


$$
L\left(E_{n}\right)=\left\langle E_{n}, h\right\rangle=\mathscr{D}^{n} h\left(\lambda_{n}\right)=t_{n} \quad n=0,1,2, \cdots .
$$

Theorem $\mathrm{C}$ implies that the system $\left\{E_{n}\right\}_{n=0}^{\infty}$ constitutes a basis in its closed linear hull in $\mathscr{F}_{r}$, by Theorem 1 the system $\left\{E_{n}\right\}_{n=0}^{\infty}$ is complete in $\mathscr{F}_{r}$, so $\left\{E_{n}\right\}_{n=0}^{\infty}$ constitutes a basis in $\mathscr{F}_{r}$ and the proof of Theorem 3 is finished.

By [14] it follows that the system $\left\{z^{n} E\left(\lambda_{n} z\right)\right\}_{n=0}^{\infty}$ constitutes a basis in $\mathscr{F}_{r}$ which is equivalent to the canonical basis $\left\{z^{n}\right\}_{n=0}^{\infty}$. We remark that under the assumptions of Theorem 2 the system $\left\{z^{n} E\left(\lambda_{n} z\right)\right\}_{n=0}^{\infty}$ does not constitute a basis for $\mathscr{F}_{r}$, because the system $\left\{z^{n} E\left(\lambda_{n} z\right)\right\}_{n=0}^{\infty}$ is even not complete in $\mathscr{F}_{r}$.

Some other results of this kind can be found in [11], [12] or [13] (see also the references in [11]). But these are all sufficient conditions for a system $\left\{z^{n} f\left(\lambda_{n} z\right)\right\}_{n=0}^{\infty}$ to be a basis in $\mathscr{F}_{r}$ and there is no similar result to Theorem 2 .

\section{REFERENCES}

1. M. G. Arsove, On the behavior of Pincherle basis functions, Pacific J. Math., 44 (1973), 13-31.

2. J. D. Buckholtz and J. L. Frank, Whittaker constants, Proc. London Math. Soc., 23 (1971), 348-370.

3. Whittaker constants, II, J. Approximation Theory, 10 (1974), 112-122.

4. M. M. Dragilev, V. P. Zaharjuta and Ju. F. Korobeinnik, A dual relationship between some questions of basis theory and interpolation theory, Soviet Math. Dokl., 15, 2 (1974), 533-537.

5. Ed Dubinsky, Linear Pincherle sequences, Pacific J. Math., 55 (1974), 361-369.

6. M. A. Evgrafov, The interpolation problem of Abel-Gončarov, GITTL, Moscow, 1954.

7. J. L. Frank and J.K. Shaw, Abel-Gončarov polynomial expansions, J. Approximation Theory, 10 (1974), 6-22.

8. A. O. Gel'fond and A.F. Leont'ev, On a generalization of Fourier series, Mat. Sbornik N. S., 29 (71) (1951), 477-500.

9. F. Haslinger, Basen in Räumen von holomorphen Funktionen, Anz. Österr. Akad. Wiss., Math.-naturw. Kl., 12 (1977), 212-216.

10. Generalized Abel-Gončarov bases in spaces of holomorphic functions, (submitted).

11. I. I. Ibragimov and N. I. Nagnibida, The matrix method and quasi-power bases in the space of analytic functions in a disk, Russian Math. Surveys, 30 (1975), 107-154.

12. Ju. F. Korobeǐnik, On a duality problem, I, Mat. Sbornik N. S., 97 (139) (1975), 191-229.

13. M. A. Kraplin, Two examples of matrix methods in the study of quasi-power bases, Sbornik Nauchno-Techn. Raboti Azovo-Chernomorsk. Inst. Mech., 10 (1957), 313-322.

14. Nguyen Thanh Van, Bases de Schauder dans certains espaces de fonctions holomorphes, Ann. Inst. Fourier, 22 (1972), 169-253.

15. A. Pietsch, Nukleare lokalkonvexe Räume, Berlin, 1965.

Received July 7, 1978.

UNIVERSITY OF VIENNA

AUSTRIA 


\section{PACIFIC JOURNAL OF MATHEMATICS}

\section{EDITORS}

DONALD BABBITT (Managing Editor)

University of California

Los Angeles, California 90024

Hugo RossI

University of Utah

Salt Lake City, UT 84112

C. C. MOORE and ANDrew OGG

University of California

Berkeley, CA 94720
J. DUgundjI

Department of Mathematics University of Southern California Los Angeles, California 90007

R. FinN aNd J. Milgram Stanford University Stanford, California 94305

\section{ASSOCIATE EDITORS}

E. F. BECKENBACH

B. H. NeUMANN

F. WOLF

K. YosHIDA

\section{SUPPORTING INSTITUTIONS}

UNIVERSITY OF BRITISH COLUMBIA CALIFORNIA INSTITUTE OF TECHNOLOGY UNIVERSITY OF CALIFORNIA MONTANA STATE UNIVERSITY UNIVERSITY OF NEVADA, RENO NEW MEXICO STATE UNIVERSITY OREGON STATE UNIVERSITY UNIVERSITY OF OREGON
UNIVERSITY OF SOUTHERN CALIFORNIA STANFORD UNIVERSITY UNIVERSITY OF HAWAII UNIVERSITY OF TOKYO UNIVERSITY OF UTAH WASHINGTON STATE UNIVERSITY UNIVERSITY OF WASHINGTON 


\section{Pacific Journal of Mathematics}

\section{Vol. 84 , No. 1 \\ May, 1979}

Michael James Beeson, Goodman's theorem and beyond ...............

Robert S. Cahn and Michael E. Taylor, Asymptotic behavior of multiplicities

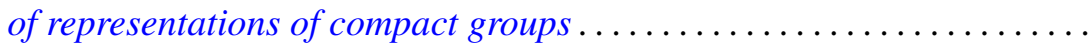

Douglas Michael Campbell and Vikramaditya Singh, Valence properties of

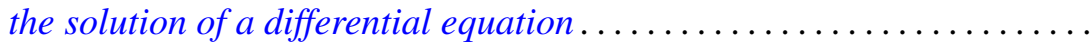

J.-F. Colombeau, Reinhold Meise and Bernard Perrot, A density result in spaces of Silva holomorphic mappings .....................

Marcel Erné, On the relativization of chain topologies .................

Le Baron O. Ferguson, Uniform and $L_{p}$ approximation for generalized

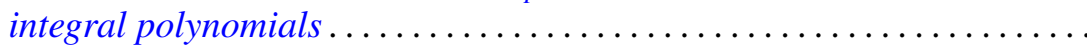

Kenneth R. Goodearl and David E. Handelman, Homogenization of regular rings of bounded index..................................

Friedrich Haslinger, A dual relationship between generalized

Abel-Gončarov bases and certain Pincherle bases .................

Miriam Hausman, Generalization of a theorem of Landau. .

Makoto Hayashi, 2-factorization in finite groups

Robert Marcus, Stochastic diffusion on an unbounded domain ........... 143

Isabel Dotti de Miatello, Extension of actions on Stiefel manifolds....

C. David (Carl) Minda, The hyperbolic metric and coverings of Riemann surfaces...

Somashekhar Amrith Naimpally and Mohan Lal Tikoo, On $T_{1}$-compactifications.

Chia-Ven Pao, Asymptotic stability and nonexistence of global solution for a semilinear parabolic equation ....

Shigeo Segawa, Harmonic majoration of quasibounded type ...

Sze-Kai Tsui and Steve Wright, The splitting of operator algebras ...

Bruce Williams, Hopf invariants, localization and embeddings of Poincaré complexes....

Leslie Wilson, Nonopenness of the set of Thom-Boardman maps ...

Alicia B. Winslow, There are $2^{\mathrm{c}}$ nonhomeomorphic continua in $\beta R^{n}-R^{n}$ 